\title{
Are we too passive in our attempts to prevent respiratory syncytial virus infection in Northern Canada?
}

\author{
Theo Moraes MD PhD FRCPC
}

$\mathrm{I}^{\mathrm{n}}$ n the current issue of the Canadian Respiratory Journal, Banerji et al (1) (pages 185-189) assessed the effectiveness of respiratory syncytial virus (RSV) prophylaxis in Nunavut. This is important work on a relevant pathogen. RSV infection has a significant impact on the health of Canadian children. RSV infection is the number one reason for hospitalization in the first few years of life $(2-4)$ and is the most frequent cause of viral death in infants worldwide (5). One per cent to $2 \%$ of all children $<1$ year of age are hospitalized in Canada each year with RSV infection (6), which corresponds to $>12,000$ Canadian infants hospitalized annually with RSV (4).

Unfortunately, current treatment approaches to RSV infection are limited. Essentially, supportive therapy is offered to improve airway clearance and maintain hydration and oxygenation (7). Prevention of infection is key.

The outlook for prevention, however, is not much better. There is no vaccine available for RSV. Although recent work suggests that an effective RSV vaccine is not unreasonable (8), the challenge of creating an immune response in the most at-risk group - young premature infants - remains significant.

Currently, the only specific intervention for prevention of RSV is passive immunization with RSV monoclonal antibody (ie, palivizumab). This treatment reduces hospitalization in high-risk infants (9) and requires monthly injections during RSV season. In the initial trial demonstrating efficacy, approximately 15 infants were treated to prevent one admission (10). Prophylaxis is not inexpensive - costs are, on average, $>\$ 6,000$ per infant per season (personal communication, K Suh, Ontario Ministry of Health and Long-Term Care). Understandably, cost is a major driving force behind recommendations of who to offer prophylaxis. If the balance of reduced admissions is financially favourable, prophylaxis is given.

Morbidity and mortality associated with RSV is increased in premature infants, and those with heart or lung disease (11); however, Canada also has unique groups with increased rates of severe RSV infection. For example, 30\% of all term Inuit infants born in northern communities are hospitalized with RSV infection in the first six months of life (12). Compounding the problem is the relatively high cost of admission for these relatively isolated babies.

The 2013 guidelines in Ontario (13) suggest offering prophylaxis to "infants $33-35$ completed weeks gestation and aged $\leq 6$ months at the start of, or during the local RSV season and who live in isolated communities where pediatric hospital care is not readily accessible and ambulance transportation is required for hospital admission". The Canadian Paediatric Society goes beyond this recommendation and suggests that all term Inuit infants $<6$ months of age at the start of the RSV season residing in remote communities be considered for prophylaxis (14).

This is the context in which Banerji et al (1) examined the effectiveness of palivizumab in Nunavut. Over the two-year period they collected data, 1647 babies were born. Given the limited access to health care in these communities, the authors had access to data from all possible hospitals that these newborns could be admitted to. They also had access to a registry that outlined who was to receive palivizumab and who actually did receive the prophylaxis. Infants were eligible for palivizumab if they were $<6$ months of age at the beginning of the RSV season with a gestational age $<36$ weeks and/or had significant cardiac or respiratory disease.

A total of 91 infants received prophylaxis and, of these, two were admitted with RSV infection. Thus, babies who received prophylaxis had a 2\% admission rate with RSV, which is comparable with healthy term babies in Canada. It is not clear how many prophylaxis-eligible infants did not actually receive prophylaxis. If one assumes, as the authors do, that $8 \%$ of infants born would be eligible for prophylaxis, of 1647 births, one would expect 132 eligible infants over two years. Thus, if 91 received prophylaxis, one can assume that $41 \mathrm{did}$ not. Of these 41 infants, five were admitted with RSV, yielding a $12.1 \%$ admission rate. This translates into a number needed to treat to prevent one admission of approximately 10 infants. This is in the range of the data used to justify RSV prophylaxis for more premature infants (9).

The study by Banerji et al (1) did not control for confounding variables that may have influenced RSV admission rates (eg, smoking, which may be different between the prophylaxis group and the nonprophylaxis group). Althugh a randomized control trial of placebo versus palivizumab would be ethically problematic, future studies should control for these variables to discern whether the beneficial effects observed are related to the biological effects of palivizumab or a combination of the biological effects and other factors associated with delivery of the prophylaxis.

Despite these shortcomings, the study by Banerji et al supports the concept that RSV prophylaxis is associated with reduced admissions in this particular group of high-risk infants. What is not clear from this work is why the admission rates for term Inuit infants are so high in the first place (12). First Nations and Inuit children experience not only increased rates of RSV admission - their health is below average on many indexes. Factors that contribute to this reduction in general health may also influence the risk of RSV admission (housing related, smoke exposure, nutritional, etc). To provide prophylaxis to $8 \%$ of infants born (the 'at risk' estimate) over the two-year time period in this study would have cost $>\$ 800,000$ for 132 infants. If we assume (somewhat arbitrarily) that one-half of the population of 1647 infants born over these two years were $<6$ months of age at the start of RSV season, the Canadian Paediatric Society recommendation - that all Inuit children in such communities should be protected - would lead to prophylaxis for approximately 820 infants over two years at a cost of $\$ 5$ million. Perhaps these dollars would be better spent in researching and addressing the determinants of health that put these infants at risk in the first place (housing, nutrition, etc) because addressing these factors for babies and their families in Nunavut may improve more than just their RSV admission rates.

The exciting news is that the high rates of RSV admission apparent in Northern Canada can be lowered with passive immunization. However, maybe we should have more than just a passive approach to address this issue.

Department of Respiratory Medicine, The Hospital for Sick Children, Toronto, Ontario

Correspondence: Dr Theo Moraes, Department of Respiratory Medicine, The Hospital for Sick Children, 555 University Avenue, Toronto,

Ontario M5G 1X8. Telephone 416-813-2196, e-mail theo.moraes@sickkids.ca 


\section{REFERENCES}

1. Banerji A, Panzov V, Young M, et al. The real-life effectiveness of palivizumab for reducing hospital admissions for respiratory syncytial virus in infants residing in Nunavut. Can Respir J 2014;21:185-9.

2. Leader S, K Kohlhase K. Recent trends in severe respiratory syncytial virus (RSV) among US infants, 1997 to 2000.

J Pediatr 2003;143(5 Suppl):S127-32.

3. Pelletier AJ, Mansbach JM, Camargo CA Jr. Direct medical costs of bronchiolitis hospitalizations in the United States. Pediatrics 2006;118:2418-23.

4. Samson L. Prevention of respiratory syncytial virus infection. Paediatr Child Health 2009;14:521-32.

5. Empey KM, Orend JG, Peebles RS Jr, et al. Stimulation of immature lung macrophages with intranasal interferon gamma in a novel neonatal mouse model of respiratory syncytial virus infection. PLoS One 2012;7:e40499.

6. Schanzer DL, Langley JM, Tam TW. Hospitalization attributable to influenza and other viral respiratory illnesses in Canadian children. Pediatr Infect Dis J 2006;25:795-800.

7. Diagnosis and management of bronchiolitis. Pediatrics 2006;118:1774-93.
8. Groothuis JR, Hoopes JM, Jessie VG, Prevention of serious respiratory syncytial virus-related illness. I: Disease pathogenesis and early attempts at prevention. Adv Ther 2011;28:91-109.

9. Prevention of respiratory syncytial virus infections: Indications for the use of palivizumab and update on the use of RSV-IGIV. American Academy of Pediatrics Committee on Infectious Diseases and Committee of Fetus and Newborn. Pediatrics 1998;102:1211-6.

10. Palivizumab, a humanized respiratory syncytial virus monoclonal antibody, reduces hospitalization from respiratory syncytial virus infection in high-risk infants. Pediatrics 1998;102:531-7.

11. Collins PL, Graham BS. Viral and host factors in human respiratory syncytial virus pathogenesis. J Virol 2008;82:2040-55.

12. Banerji A, Lanctôt KL, Paes BA, et al. Comparison of the cost of hospitalization for respiratory syncytial virus disease versus palivizumab prophylaxis in Canadian Inuit infants. Pediatr Infect Dis J 2009;28:702-6.

13. Respiratory Syncytial Virus Prophylaxis for High-Risk Infants Program 2013 [cited 2013 October 2013] <www.health.gov.on.ca/ en/pro/programs/drugs/funded_drug/fund_respiratory.aspx $>$ (Accessed October 2013).

14. Robinson J. Preventing respiratory syncytial virus infections. Paediatr Child Health 2011;16:487-90. 


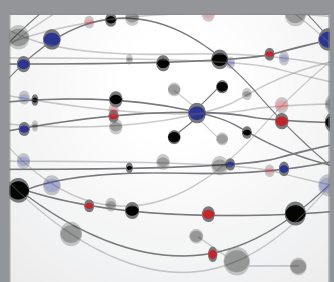

The Scientific World Journal
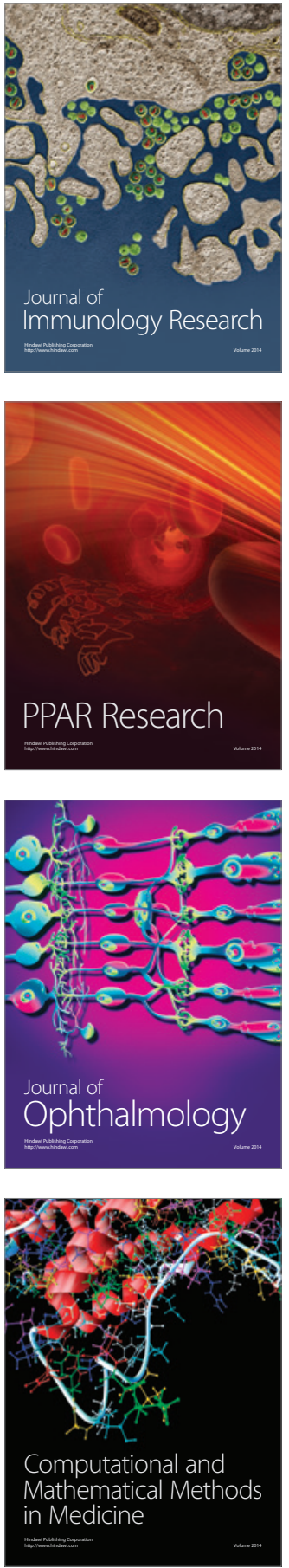

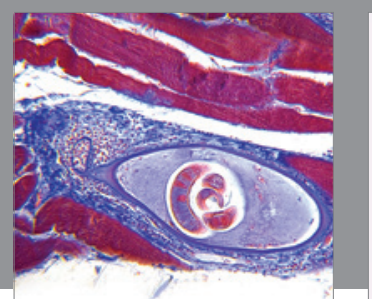

Gastroenterology Research and Practice

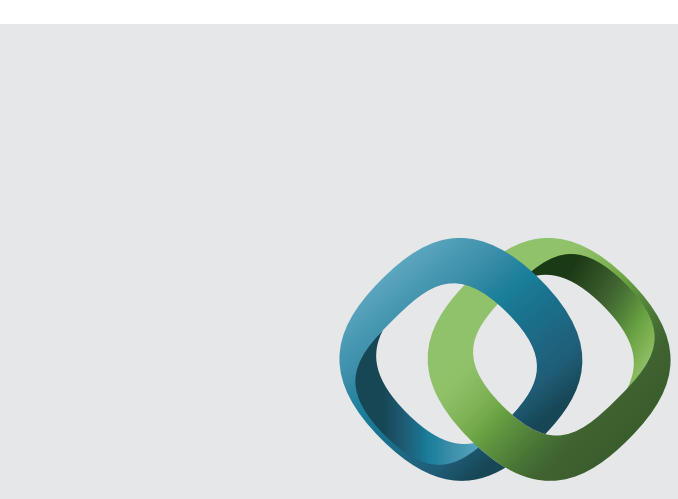

\section{Hindawi}

Submit your manuscripts at

http://www.hindawi.com
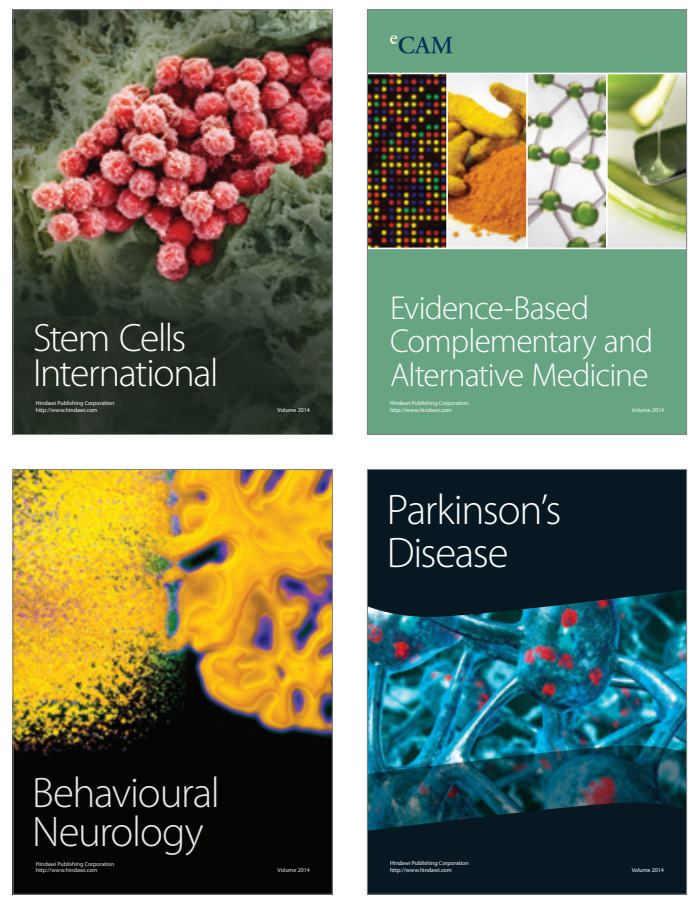
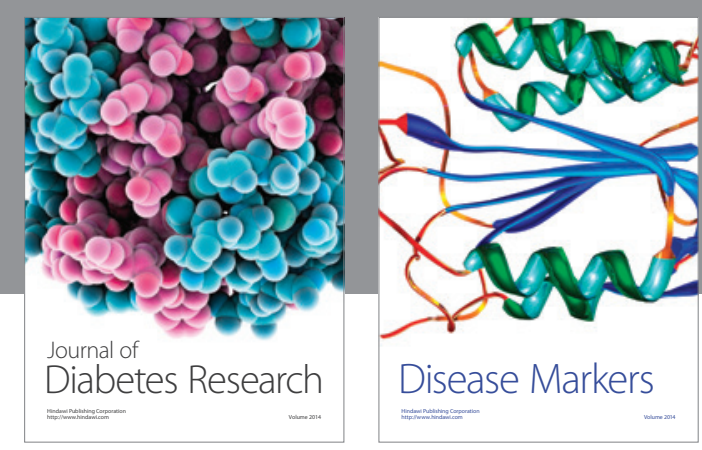

Disease Markers
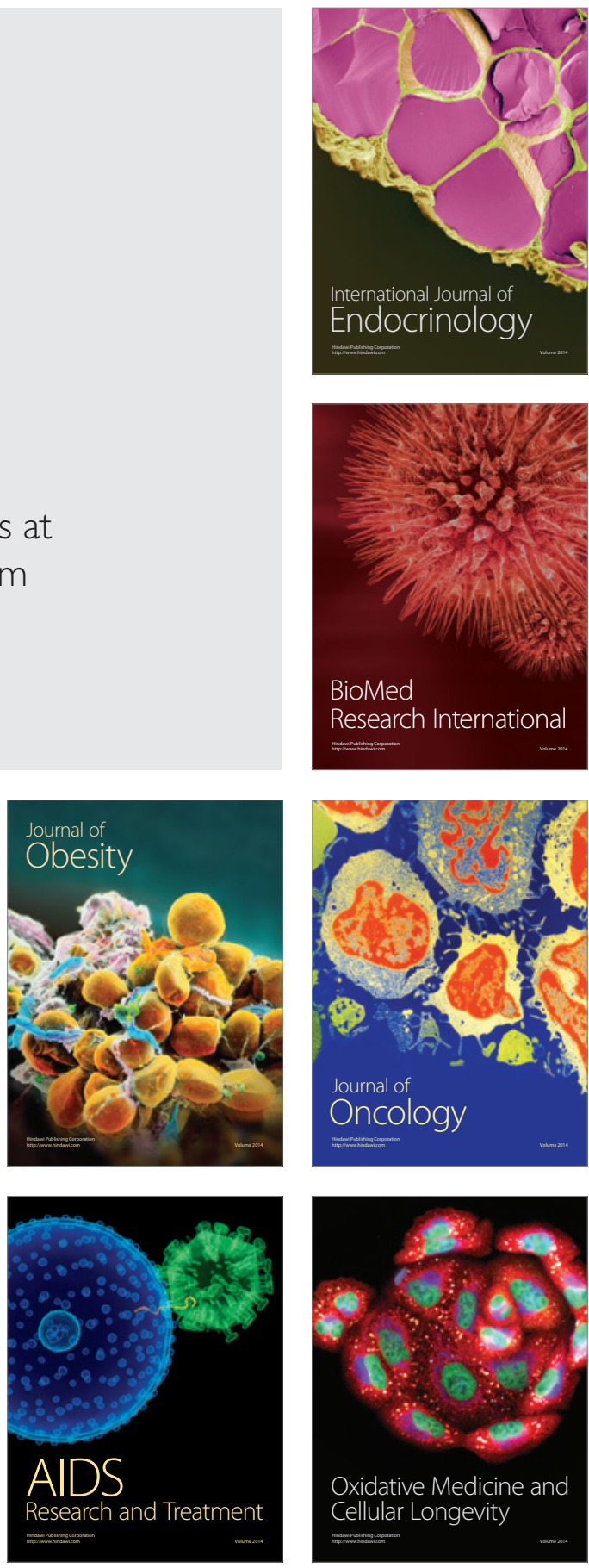